\title{
La moda y sus figuras de mujer: tópicos para leer a Domingo Sarmiento en momentos fundacionales de la nación en Argentina ${ }^{1}$
}

\author{
Fashion and female figures: Topics to read Domingo \\ Sarmiento at nation founding moments in Argentina
}

Recibido: 24 de noviembre de 2014 - Revisado: 24 de junio 2015 - Aceptado: 29 de septiembre de 2015

Nathalie R. Goldwaser Yankelevich ${ }^{2}$

\section{Resumen}

En el presente escrito se afirma que en la primera mitad del siglo XIX, la mujer estuvo invisibilizada en la fundación de la nación en Argentina, qua sujeto de derechos políticos. Sin embargo, la intelligentsia de aquella época la notaba factor de transformación de nuevas tendencias aunque también de conservación de ciertas costumbres. Domingo F. Sarmiento ha dejado testimonios insoslayables del lugar de las figuras de la mujer en relación con la moda no solo en cuanto a estilos, indumentaria y costumbres, sino también en novedades culturales, sociales y políticas. La moda, a su vez, participó de la problemática de la época: la tensión entre la civilización y la barbarie, las diferencias entre los sexos y su vínculo problemático sobre la igualdad y la libertad.

\section{Palabras clave}

Argentina, siglo XIX, Domingo Sarmiento, modas, costumbres, figuras de la mujer.

\begin{abstract}
In this paper 1 it is stated that in the first half of the nineteenth century, the woman was invisible in the foundation of the nation in Argentina, qua subject of political rights. However, the intelligentsia of that time notices she was a factor of transformation of new trends but also of conservation of certain customs. Domingo F. Sarmiento has left inescapable evidence of the place of figures of women not only in terms of styles, clothing and customs, but also in cultural, social and political developments. Fashion, in turn, was part of the problems of the time: the tension between civilization and barbarism, the differences between the sexes and their problematic relationship of equality and freedom.
\end{abstract}

\section{Keywords}

Argentina, XIX century, Domingo Sarmiento, fashion, customs, figures of women.

\footnotetext{
${ }^{1}$ Artículo desarrollado en el marco del proyecto posdoctoral financiado por el Consejo Nacional de Investigaciones Científicas y Técnicas (Conicet) titulado "Diferencia sexual en los discursos político-ideológicos fundacionales de la nación en el Río de la Plata y Nueva Granada, 1835-1853. Las figuras del 'hombre'", Buenos Aires, Argentina.

${ }^{2}$ Doctora en Ciencias del Arte por la Universidad de París I Panthéon Sorbonne, París, Francia; y Doctora en Ciencias Sociales de la Universidad de Buenos Aires, Buenos Aires, Argentina. Magíster en Comunicación y Cultura; y Licenciada en Ciencia Política de la Universidad de Buenos Aires. Ayudante regular de la materia Historia del Arte y del Diseño (Facultad de Arquitectura, Diseño y Urbanismo, Universidad de Buenos Aires). Correo electrónico: nathalie.goldwaser@gmail.com

Para citar este artículo use: Goldwaser, N. (2015). La moda y sus figuras de mujer: tópicos para leer a Domingo Sarmiento en momentos fundacionales de la nación en Argentina. Revista Civilizar Ciencias Sociales y Humanas, 15(29), 59-72.
} 
Como toda moda, que crea su propia saturación, mata su objeto antes de haber tenido tiempo suficiente para enunciarse claramente.

Perrot, 1988

Las configuraciones alrededor de las relaciones entre los sexos explicarían un aspecto de la historia de una nación. Afirmación contundente pero no siempre de fácil demostración. Estas relaciones pueden observarse a través de los documentos históricos que aluden a la moda, las costumbres de la época y su politización, no solo aquellos de corte periodístico sino también los literarios.

Revisaremos aquí muy sucintamente algunos estudios contemporáneos que analizan el papel que desempeñó la moda y las costumbres respecto de la política, no solo en nuestro continente sino también en Europa, dado que en aquella época la observancia, influencia e imitación de algunos países del "viejo mundo" tenían un lugar preponderante a la hora de diseñar la propia postura.

Vale la pena adelantar que por moda entenderemos no solo los efectos producto del vestir, la indumentaria y usos, sino además una práctica ligada a la incorporación de lo novedoso, las nuevas tendencias en materia política, literaria, artística y cultural, en oposición a las costumbres. Mientras estas últimas se vinculan a una repetición rutinaria de una eterna imitación conservadora; la moda, en nuestro sentido, es también una imitación pero inesperada, que se enlaza y asocia con el pasado, con el presente y con el porvenir. La consideración del papel de la moda, en tanto incorporación de lo nuevo, es esa combinación entre lo que se deja y se retoma del pasado, las exigencias del presente y su indefectible transformación en el futuro, si quiere permanecer siendo moda en lugar de convertirse en su opuesto, la costumbre.

El objetivo del presente artículo es poder dar cuenta de que la moda lejos de ser inmutablemente un fenómeno frívolo, distorsión y apariencia de la realidad; en la historia política de la Argentina decimonónica, por el contrario, formó parte de aquellos discursos que crearon y fundaron las bases del Estado, la nación y la ciudadanía. La moda evidencia no solo las concepciones y funciones de la mujer en tanto figuras presentes en los discursos decimonónicos, sino también su proyección en cuanto a los aspectos políticos de la nación argentina en ciernes.

En el juego de aparición/desaparición de las ideas políticas y de las concepciones de la moda, no siempre pero con frecuencia enlazado con las figuras de la mujer y las costumbres, leemos la persistencia de temas no saldados por nuestra época. En síntesis, creemos que la invocación a estos conceptos en el Río de la Plata se convierte en una arista original para poder reconstruir un aspecto de la historia política argentina, y a la vez nos permite rastrear cuáles son las herencias que el imaginario de la época nos legó.

Para ello, tomaremos algunos ejemplos representativos de textos pertenecientes a Domingo F. Sarmiento para poder reportar cómo pensó los elementos que debían componer su proyecto político de nación republicana utilizando observancias hacia la moda, la indumentaria, las costumbres y las figuras de la mujer que aparecen en sus obras.

Por último, quisiéramos reflexionar sobre ese lugar que obtuvo la moda, la coquetería y las costumbres públicas, la articulación con la diferencia de los sexos y su relación con la política. Sostenemos que estas operaciones son constitutivas de nuestras culturas y sociedades $\mathrm{y}$, por lo tanto, históricas e historizables, posibles de reconstruirlas a través de los discursos político-ideológicos fundacionales de la "nación" en Argentina.

Siguiendo la obra de Joan Scott(2012), nos interrogamos: ¿cómo ha sido vista la diferencia sexual, en tanto fenómeno indeterminado, en 
este periodo y qué rol cumplió la moda en esas configuraciones?

\section{Los conceptos políticos, la diferencia de los sexos y la moda}

Varios estudios demuestran que durante el siglo XIX "el ser y el parecer se debían corresponder", que la feminidad era una cuestión de apariencias ${ }^{1}$, que la mujer era el "sexo débil" y que su frivolidad se debía al desinterés por la cosa pública. Al menos ese era el estereotipo que durante el siglo XIX se pregonaba.

La relación entre los sexos y entre las condiciones sociales se evidenciaba en parte por la vestimenta. No solo marcaba el sexo biológico (por lo tanto, en la mayoría de los casos el travestismo -de ambos sexos- era penado por la ley, en otros penado por la moral), sino además el estatus económico, la ideología, la religión, la nacionalidad y el poder. "Tener el pantalón puesto", por ejemplo, es una expresión del siglo XVII pero que perdura hasta la actualidad e implica afirmar que quien lo posee es el que detenta el poder, la decisión última. En este sentido, Christine Bard en Historia política del pantalón (2012) rastrea desde el siglo XVII, hasta el siglo $\mathrm{XX}$, ese vínculo entre la política y el vestir.

Esta autora es la que anota precisamente que desde la antigüedad, la diferenciación de las apariencias según el sexo es una ley fundamental por la que velan las autoridades religiosas y políticas. Así lo demuestra a través de un pasaje de La Biblia (Deuteronomio 22: 5): “Una mujer no llevará ropas masculinas y un hombre no se pondrá ropas de mujer, quien actúa de esta manera es una abominación para Yavé, tu Dios". La confusión de los sexos forma parte de los grandes miedos en Occidente desde la Edad Media (Bard, 2012, p. 16).

No solo en Europa, también del otro lado del océano. Más particularmente en el Río de la Plata. Para Víctor Goldgel en Cuando lo nuevo conquistó América. Prensa, moda y literatura en el siglo XIX (2013), el proceso de emancipación política del Río de la Plata se asocia con el surgimiento de un nuevo medio (el periódico), la consolidación de un dispositivo social que opera una renovación constante de objetos y prácticas (la moda) y la continuidad entre dos formaciones discursivas del periodo (la Ilustración y el Romanticismo). Afirma que estos tres elementos se legitimaron sobre el soporte de lo novedoso, siendo "lo nuevo" el objeto de reflexión permanente en la época de la naciente era republicana.

"Con los experimentos liberales de comienzos del siglo XIX, las élites hispanoamericanas se vieron obligadas a redefinir sus vínculos con la tradición española y a actuar sobre la base de las nuevas realidades políticas" (Goldgel, 2013, p. 16). De este modo, las costumbres y la tradición no iban de la mano. Las costumbres se convirtieron en una arena de lucha y transformación ${ }^{2}$. Lo nuevo como imitación de algo ya existente en otro lugar pero de lo que no se tiene experiencia, tuvo su espacio material en la moda confundiéndose con el concepto "progreso". Y el periódico era la plataforma ideal para reflexionar acerca de las transformaciones culturales.

Las élites hispanoamericanas se hicieron eco del ideal europeo: el consumo y la moda fueron con frecuencia defendidos como medios para alcanzar la vida civilizada. En el Río de la Plata, por ejemplo, fue la Generación del '37 notoriamente la que tuvo la preocupación por forjar una nación "civilizada" desde los modelos de la modernidad occidental. Las ideas de civilización y progreso tenían la impronta del pensamiento francés, dada entre los años 1830 y 1848. Estas corrientes lograron desplazar la influencia del utilitarismo traído de Inglaterra a través de Jeremy Bentham ${ }^{3}$.

Siguiendo a Goldgel (2013), hay un estereotipo del letrado como guardián y administrador del orden de los signos y esto implicaba incluso que no siempre los intelectuales de la época, ante la lucha entre civilización y bar- 
barie, estuvieran del lado de la primera. Agregamos que, en muchos casos, la élite ilustrada cumplió la tarea de ser traductora de estas nuevas tendencias extranjeras, adaptándolas a las realidades locales. Para Susan Hallstead (2004) en la producción literario-periodística de la Argentina decimonónica, la alusión a las modas extranjeras -principalmente europeascomo parte del proyecto nacional puede ser vista como una forma alternativa de propaganda nacionalista (p. 54). Algo similar sostiene Root (2014) al aseverar que la moda ocupó un campo de batalla de significantes, en particular a los jóvenes patriotas les permitió distanciarse de las reliquias del colonialismo español.

Según Masiello (1997) el Romanticismo habilitó el espacio de la imaginación, abriendo camino al discurso sobre lo femenino y la atracción hacia la figura de la mujer. También señala que es a partir del Romanticismo venido de Europa que se puede entender por qué las mujeres en la imaginación política de los hombres del siglo XIX, simbolizaban las virtudes de la nacionalidad y ponían en cuestión las injusticias sociales. Una de nuestras hipótesis que hemos investigado ${ }^{4}$ sostiene que cuando se pone la atención en el romanticismo político se olvida la función de la mujer, y cuando se recuerda la función de la mujer se desatiende el contexto político de aquella corriente.

Molina (2005) considera que si insistían en la ropa femenina era porque la mujer debía desempeñar un rol cardinal como reproductora de las costumbres democráticas en el seno de la familia pero, al decir de la autora, "la igualdad de derechos no remitía a ella sino al sector masculino adulto" (p. 160). Creemos que aquella invocación problematiza la noción de igualdad (política) y que ese conflicto se vislumbra precisamente a través del papel que ejerció la moda en esos discursos.

Aquella insistencia se puede corroborar en las dos publicaciones más prominentes sobre la temática de esta juventud romántica argentina de la Generación del '37 como lo fueron: La moda. Gacetín de música, literatura, costumbres y poesía (editada semanalmente en Buenos Aires desde finales de 1837 hasta abril del año siguiente) y el periódico quincenal El Iniciador (que surge en Montevideo tras el cierre de aquella y el exilio de varios de sus miembros por la persecución del gobierno de De Rosas) ${ }^{5}$. Es decir, no solo el género periodístico fue transmisor de estos posicionamientos, sino también existen menciones en géneros literarios tales como las novelas románticas, las autobiografías y los ensayos políticos. En este estudio nos detendremos en algunos escritos de Domingo F. Sarmiento.

\section{Las fuentes primarias: la vestimenta en el conflicto político}

\section{Un breve contexto histórico-político.}

Como todos los periodos históricos, el que nos ocupa no fue sin turbulencias. Pretender resumirlo resulta una empresa ardua y quimérica. No podremos, entonces, ser exhaustivos para la presente publicación. Para ser sintéticos, durante la primera mitad del siglo XIX en el Río de la Plata, las novedades en política como en costumbres eran frecuentes y complejas.

Una figura política se destaca durante ese periodo: Juan Manuel de Rosas quien fuera gobernador de Buenos Aires en dos ocasiones: entre 1829 y 1832 , y desde 1835 hasta 1852 , en ambos casos con poderes extraordinarios sobre la provincia; asumiendo además la representación de todas las demás frente a los países extranjeros.

El aspecto central de gobierno rosista va a ser la paulatina transición hacia la instauración del federalismo. Recordemos que en esta etapa aún no había sido consolidado un Estado nación argentino que nucleara a todas las provincias en una unidad política más grande.

En 1835, Juan Manuel de Rosas iba a dar comienzo a su segundo periodo como gober- 
nador de la provincia de Buenos Aires elegido por la Sala de Representantes; el mismo, iba a prolongarse durante dos décadas, utilizando una fórmula novedosa que lo dejaría en una evidente condición de poder acumulado: no solo la designación se hacía por el término de cinco años (lo cual implicó modificar la ley electoral dictada en 1823), sino que se depositaba "toda la suma del poder público" de la provincia a De Rosas con la única condición de que conservara, defendiera y protegiera la religión católica apostólica romana; y sostener también la causa de la federación.

Una de las novedades institucionales de la época, y que va a reflejarse fuertemente en la forma de vestir, será el plebiscito de 1835 celebrado solamente en Buenos Aires para obtener la opinión de todos los ciudadanos respecto del otorgamiento de aquel poder a De Rosas, los resultados fueron aplastantes.

El consenso no solo se evidenció en términos institucionales, además se erigió una nueva modalidad para expresarlo ${ }^{6}$. Para uniformar las opiniones bajo la causa de la "Santa Federación", en el plano de lo visible, el rosismo impone el uso obligatorio de la divisa punzó, "una forma de vestir federal", que incluía el tradicional poncho y chaqueta, utilizado básicamente por los sectores populares pero también mediante sombreros, guantes o peinetas con la estampa de De Rosas, o bien la exhibición de objetos de uso cotidiano como vajillas, monederos y relicarios con su retrato (Ternavasio, 2009, p. 203), todo ello supuestamente reflejaba la adhesión a la causa del federalismo.

Para Marcelo Marino (2013) el vestido y sus accesorios fueron fundamentales en la imposición del discurso político y en el funcionamiento de los mecanismos de control puestos en marcha con De Rosas. La eficacia del dispositivo de la cinta color rojo punzó hizo que se transformara en el elemento indispensable e ineludible en la práctica del vestir cotidiano, porque encarnó un programa de formación y de educación por la patria, además de ser motivo de orgullo y de exaltación del orden federal (pp. 20-21).

En el plano del poder de policía, hará uso de la Sociedad Popular Restauradora (más conocida como Mazorca), a la radicalizada de sus seguidores, que se encargará de reprimir con ferocidad la disidencia a la figura del "Restaurador de las Leyes".

En un clima de creciente violencia e inestabilidad política, De Rosas inicia su nuevo mandato con el firme objetivo de crear un orden interno, para lo cual, va a hacer uso de una dura persecución a los opositores a su gobierno, calificándolos a todos ellos -a pesar de las nítidas diferencias que se pueden apreciar entre los unitarios, federales no rosistas o los jóvenes de la Asociación de Mayo- de "salvajes e inmundos unitarios".

\section{La Generación del 37 y la mujer.}

En aquel contexto, muchos de los opositores al rosismo serán asesinados, algunos de ellos lograron tomar el camino del exilio (principalmente en Montevideo y, como lo hiciera Sarmiento, en Chile) para continuar desde allí su enfrentamiento con el conductor de la política nacional, tal es el caso de los integrantes de la Generación del 37, entre los que se encontraban, Esteban Echeverría (padre fundador), Juan B. Alberdi, José Mármol y, aunque desde la provincia de San Juan, también se suele incluir a Domingo F. Sarmiento ${ }^{7}$.

Dicha generación, en un escenario de censura y exilio durante el régimen de De Rosas, hizo contribuciones al mundo de las ideas filosófico-políticas que fueron esenciales a la hora de la formación del Estado nación, la ciudadanía y otras instituciones modernas en el territorio argentino. Pero el interés por la Generación del 37 -grupo cuyo pensamiento oscila entre la razón ilustrada y la razón romántica- no solo se debe a su "reflexión 
explícita sobre la nación" y la nacionalidad (Halperín-Donghi, 2004), sino además por ser los primeros pensadores de la élite que incorporaron en su escritura a la mujer, muchas veces, en el epicentro de sus discursos en vinculación directa con cuestiones que remitían a la esfera de lo político.

Nos interesan los textos escritos por hombres de élite porque allí es factible observar " $e l$ poder del lenguaje, donde la mujer aparece como soporte mudo, como partícipe de un intercambio que sin embargo no protagoniza" (Arfuch, 2008, p. 131). Aquellos hombres se caracterizaron por haber tenido un lugar prominente en la historia de Argentina; por su ideología republicana y liberal, han adscripto al novedoso pensamiento romántico europeo (en particular al de Francia, Inglaterra, Alemania y España) ${ }^{8}$; han asumido el binomio "civilización-barbarie" para interpretar su presente e intentar transformarlo; y, por último, pretendiendo "escribir en nombre de", a su vez, han tratado cuestiones que afectaron directamente a la condición de la mujer.

Dado que el régimen rosista, lejos de propugnar por la instalación de una República desde el ejercicio de la libertad de inteligencia creadora, se basaba en el enfrentamiento, la censura de pensamiento, la persecución y la imposición de costumbres (Botana, 1997), muchos de los discursos de la Generación del '37 fueron crípticos al intentar escapar a las reglas de la censura.

\section{Los colores políticos para la República posible}

Para Goldgel (2013) las publicaciones La Moda... y El Iniciador eran frívolas pero no por eso inofensivas. Lo frívolo tenía como función hacer leer lo serio, esto es, crear un público lector que solo más adelante tendría la capacidad de leer bien (p. 134). La moda no era solo un señuelo para atraer lectores o convencerlos de sus ideas. La moda tenía como virtud su relación estrecha con los avances del siglo.
Dado que han sido ya muy estudiados los dos periódicos en mención ${ }^{9}$, esta exposición la centraremos en las observaciones hechas por $\mathrm{D}$. F. Sarmiento (1811-1888), en particular aquellas en las que relaciona la vestimenta, las costumbres, las modas y la cuestión política de su tiempo.

Cabe destacar en esta línea, la investigación de Susan Hallstead (2004) en la que examina en los primeros números de El Progreso -periódico dirigido por Sarmiento durante su exilio en Santiago de Chile- cómo la descripción de modas extranjeras (Sarmiento se ocupa mayormente, pero no en exclusiva, de la moda femenina) formó parte de la constitución temprana de los conceptos de "cultura" y "civilización" en oposición a "barbarie". La autora demuestra que el sanjuanino modelaba una noción de identidad argentina a través del uso de las modas junto a una determinada concepción del cuerpo y la voz femeninos.

No obstante, además de exponer y resaltar la función política que la moda cumplía en aquellas literaturas; pretendemos también demostrar cómo mediante una temática supuestamente frívola (y en apariencia despojada de las discusiones polémicas y "serias" para la construcción nacional), Sarmiento reflexionaba sobre dos conceptos caros para la política: la libertad y la igualdad. Recorrido que puede explicarse precisamente vinculando las figuras de la mujer con el tema de la moda, dado que ellas evidencian a las claras estos conceptos porque encarnan un universal particular (Fraisse, 1996) ${ }^{10}$.

\section{Sarmiento, traductor de una tran- sición.}

De su vida privada se conocen varios detalles porque el propio Sarmiento se encargó de dejarlos por escrito. De ellos, aprovecharemos aquellos pasajes que establecen el vínculo directo entre sus pareceres de la vida privada y el objetivo político de su autobiografía porque 
al decir del autor, la "historia colonial de su familia" es en parte también la historia política de su patria.

Lo que sigue es la transición lenta y penosa de un modo de ser a otro; la vida de la República naciente, la lucha de los partidos, la guerra civil, la proscripción y el destierro. A la historia de la familia se sucede, como teatro de acción y atmósfera, la historia de la patria (Sarmiento, 1953, 1850, pp. 197-198).

Esta frase no encierra solo una metáfora. Es también una declaración política acerca del papel que tienen las costumbres en la consecución de un objetivo. La historia que reivindica es la que gira alrededor de su madre y hermanas. En Recuerdos de provincia aparecerá esta evidencia de la articulación entre costumbres, modas y progreso. Con la excusa de referirse al cambio que habían hecho en las habitaciones de su casa sanjuanina, Sarmiento comenta que "hubo una revolución interior que costó dos años de debates, y a mi madre gruesas lágrimas, al dejarse vencer por un mundo nuevo de ideas, hábitos y gustos que no eran aquellos de la existencia colonial" (Sarmiento, 1953, 1850, p. 190).

Sobre sus hermanas carga la evidencia del paso de un mundo colonial a otro nuevo, moderno. Sarmiento pretende explicar el paso del tiempo como un movimiento ineluctable de la historia en el que la mujer está indefectiblemente implicada. Son ellas las que -con una revolución interior- "se dejan vencer por un mundo nuevo de ideas" (Sarmiento, 1953, 1850, p. 190). El republicano Sarmiento desliza uno de los puntos dilemáticos en el que se debatieron estos hombres: las nuevas ideas a las que adscribían y su contradicción con el apego al terruño, a la vida cotidiana. Anticlerical y moderno, en la escritura de Sarmiento se escurre la ambigüedad en que estaban sumidos los hombres del siglo. Esta ambigüedad será evidente en la tópica de las costumbres de la cual la mujer es una de las principales protagonistas. El párrafo anterior continúa así:
[...] los primeros síntomas con que las revoluciones sociales que opera la inteligencia humana en los grandes focos de civilización, se extienden por los pueblos de origen común, se insinúan en las ideas, y se infiltran en las costumbres. [...] El tiempo iba a llegar en que había de mirarse de mal ojo y con desdén la industriosa vida de las señoras americanas, propagarse la moda francesa, y entrar el afán en las familias de ostentar holgura (Sarmiento, 1953, 1850, p. 190).

Para Sarmiento, las nuevas ideas se plasman primero en las costumbres y repercuten luego en el cambio de situación política y social de un pueblo. Sin embargo, esta referencia a las hermanas (y a otros miembros de la familia) es en Sarmiento el pretexto y la oportunidad para trocar su autobiografía en un ensayo netamente político y performativo:

Estas ideas de regeneración y de mejora personal, aquella impiedad del siglo XVIII, ¡quién lo creyera! entraron en casa por las $c a-$ bezas de mis dos hermanas mayores. No bien se sintieron llegadas a la edad en que la mujer siente que su existencia está vinculada a la sociedad, que tiene objeto y fin esa existencia, empezaron a aspirar las partículas de ideas nuevas de belleza, de gusto, de confortable, que traía hasta ellas la atmósfera que había sacudido y renovado la revolución (Sarmiento, 1953, 1850, p. 191; cursiva del autor).

Pero aquí, nótese que para Sarmiento si bien la mujer "siente" su vinculación con lo social, el cambio (la revolución en ella) se da solamente en la faceta de la coquetería y la estética.

\section{Facundo o la pelea por los colores de la civilización y la barbarie.}

Ampliamente estudiado, aunque sin agotar sus interpretaciones, Facundo civilización y barbarie se redactó según el propio Sarmiento en un espacio de pocos días -fruto de un arrebato romántico-, publicado como folletín en 1845 en las páginas de $E l$ Progreso $^{11}$. Fue el libro emblemático de una era y de una generación en la 
historia argentina (e hispanoamericana). Supo no solo resumir en las páginas de su obra todos los temas centrales del pensamiento social, cultural y político de la nueva generación argentina, sino también dar una interpretación general -la primera- de la historia argentina.

Al decir de José Ingenieros, "Facundo es el clamor de su cultura moderna contra el crepúsculo feudal" (1928, pp. 5-6). No obstante, lejos de ser un decadente, Sarmiento sentirá la necesidad de explicar el presente por el pasado; única manera de reflejar el porvenir. Y en este vaivén, la moda, la indumentaria, con sus colores y formatos, tendrán un papel insospechado. El capítulo octavo de Facundo... denominado "Ensayo", con la excusa de arremeter contra la insignia punzó, asevera:

Cada civilización ha tenido su traje, y cada cambio en las ideas, cada revolución en las instituciones, un cambio en el vestir. Un traje la civilización romana, otro la Edad Media; el frac no principia en Europa sino después del renacimiento de las ciencias; la moda no la impone al mundo, sino la nación más civilizada; de frac visten todos los pueblos cristianos, y cuando el sultán de Turquía, Abdul Medjil, quiere introducir la civilización europea en sus Estados, depone el turbante, el caftán y las bombachas, para vestir frac, pantalón y corbata.

Los argentinos saben la guerra obstinada que Facundo y Rosas han hecho al frac y a la moda. El año 1840 un grupo de mazorqueros rodea en la obscuridad de la noche a un individuo que iba con levita por las calles de Buenos Aires (Sarmiento, 1967, 1845, pp. 120-121)

Porque si -como dice el sanjuanino- toda civilización se expresa en trajes, y cada traje indica un sistema de ideas entero, los colores de la nación argentina cívica que él pretende construir son los que contienen las ideas fundamentales para la República: dos cintas celestes y una blanca, que simbolizan a la revolución de la independencia argentina y que significan “ijusticia, paz, justicia!” (Sarmiento, 1967, 1845).
Frente a estos dos colores, aparece la "cucarda colorada", que para él se traduce en "terror, sangre, barbarie". Y rastrea de manera geohistórica el recorrido de la cinta colorada. Concluye que: al principio, fue un color de los entusiastas que terminó uniformando la opinión, que gracias a las nuevas modas se abandonó pero que el poder de policía se encargó de recordar el motivo de su uso. Para él solo hay un país europeo culto en el que el colorado predominó, se refiere al gorro frigio del liberto adoptado por la Revolución francesa. El resto que emplea este color grana, colorado o púrpura -desde Argelia, Túnez, Turquía, Marruecos, Japón, España y su monarquía que izaba una bandera colorada, pasando por Chile y sus caciques de Arauco con mantas y ropas coloradas porque "este color agrada mucho a los salvajes" hasta llegar a los ejércitos de De Rosas que visten de colorado- tiene un vínculo común: adscribir a un régimen de violencia política y oponerse a la República, es decir, al sistema de la libertad.

Otra situación en la que enlaza la indumentaria con esta disputa política sucede en el capítulo en el que muere Facundo y asume el poder De Rosas. Y allí aparecen las mujeres, en particular "la influencia de las negras" a favor de su gobierno, ellas encarnarían el pre-texto a través del cual el autor demuestra que el gobierno del tirano ha sido apoyado y legitimado por quienes deberían haber luchado por la libertad. A falta de soldados, estaba lleno de "negras entusiastas vestidas de hombres para engrosar las fuerzas. La adhesión de los negros dio al poder de [De] Rosas, base indestructible" (Sarmiento, 1967, 1845, p. 225).

\section{Viajes.}

Por último queremos referir dos menciones sobre la moda, la indumentaria y las costumbres políticas y sociales de dos territorios completamente diferentes: Francia y Perú. En Viajes a Europa, África y América, expedición pedagógica que realiza Sarmiento, escrito en 1851 en el género epistolar, se encuentran tex- 
tos ocupados en religión y educación, hábitos y eventos sociales.

El sanjuanino describirá suestadía enParís. Entre las cosas que le llaman profundamente la atención están los "placeres públicos" porque estos ejercen "influencia sobre las costumbres de la nación" (Sarmiento, 1996, 1846, p. 122). Para el autor, Francia "sus ideas y sus modas, sus hombres y sus novelas. Son hoy el modelo y la pauta de todas las otras naciones" (p. 123). Y para responder a la pregunta por si se pretendía en aquella época, en aquel imaginario, imitar o emular, Sarmiento con sagacidad nos aclara:

[...] y empiezo a creer que esto que nos seduce por todas partes, esto que creemos imitación no es sino aquella aspiración de la índole humana a acercarse a un tipo de perfección, que está en ella misma y se desenvuelve más o menos, según las circunstancias de cada pueblo $[\ldots]$ (p. 123).

Esta reflexión, se la sugieren los bailes públicos de París, en tanto establecimientos públicos. "Compónense estas de todas las clases de la sociedad, más o menos ínfimas según el día; [...] Damas mui comme il faut [decentes] asisten como espectadores" (pp. 124-125).

A partir de aquí comienza una exquisita descripción de una persona en particular entre los asistentes del baile: La Rigolette, una de las artistas que trabajaba en los bailes de época. Para culminar en una observación acerca de la igualación de las condiciones sociales:

La Rigolette váse agitando, animándose, perdiendo el sentido y las formas humanas. [...] Es la fiebre, la convulsión del placer, la enajenación del poseído, que ha dejado de presidir a los movimientos del cuerpo, y se abandona a otra alma que la suya que está haciendo cosas sobrehumanas, no soñadas (Sarmiento, 1996, 1846, p. 124).

Ya el párrafo da indicios de lo que va a desplegar: en aquel baile se borran, desaparecen las diferencias ("pierden las formas y sentidos" como el abandono del sentido de enajenación por parte del poseído). Si aquello era una dramatización escandalosa, no obstante los bailes proveen una imagen positiva porque

[...] la sociedad se igualiza, las clases se pierden, la mujer de clase ínfima se pone en contacto con los jóvenes de alta alcurnia, las modales se afinan, y la unidad y homogeneidad del pueblo queda establecida; el público se constituye, y una miaja de gloria cae también a los pies de la mujer del bajo pueblo, entre los placeres con que aturde su miseria, o su vileza. [...] aquel lujo y aquel gusto en fin prodigado en el lugar que el roto o la hija del artesano de París llama suyo por un momento, concluyen por ennoblecer su espiritu, iniciarlo en la civilización, y hacerle aspirar a una condición mejor (Sarmiento, 1996, 1846, p. 124; cursiva del autor).

Este es el movimiento que se inicia, aunque se aspira a que rebalse el espacio placentero del baile, para que se derrame en la sociedad. Allí está de nuevo, la mujer que testimonia un pasaje, que protagoniza una sociedad-otra, una modernidad homogeneizante de las diferencias de sexo, clase, cultura, raza. Y como pensador de la modernidad, Sarmiento no puede dejar afuera aquella otra esfera, el mundo privado. A esta esfera le reserva un párrafo elocuente:

París es por otra parte poco ceremonioso en materia de costumbres privadas, y sería largo recorrer la escala que media entre la prostituta y la mujer casada, entre cuyos extremos se encuentran gradaciones del matrimonio, admitidas por la sociedad, justificadas por las diversas condiciones, y por tanto respetadas. De aquí nace a mi juicio la cultura de las mujeres en Francia, la gracia infinita de la parisiense, y el vestir igual, en su, caprichosa variedad, de todas las clases de la sociedad. De aquí viene también aquella injerencia de la mujer en todos los grandes acontecimientos de la historia de esta nación (Sarmiento, 1996,1846, pp. 125-126; cursiva del autor).

Párrafo elocuente: nos muestra a un Sarmiento absorto en la contemplación de la "civilización" parisina, opuesta a la "barbarie" 
americana. Y como parte de ella, una condición de la mujer que la "habilita" por sobre "las debilidades de su sexo" a tener influencia en los acontecimientos de la historia de la nación, tal como sigue el párrafo.

Por último, y con intenciones comparativas, tomamos otro ejemplo en que la mujer logra obtener libertad. Nos referimos a las observaciones que hiciera Sarmiento de la figura de la mujer limeña denominada "la tapada". Aquí encontraremos, no el escritor melancólico de los tiempos de la infancia, la época de la colonia, sino aquel preocupado por la emancipación e interrogándose por cómo mantener el ser nacional en su formato original y único. Cómo evitar pasar de la colonización a la imitación europeizante sin mediaciones. Sarmiento es consciente de este contraste: "Desgraciadamente la civilización y el progreso de las ideas, abren cada día honda brecha a la originalidad antigua, y el colorido desaparece en presencia de la moda y de los usos europeos" (Sarmiento, 1848, pp. 9-10). Sin embargo, en Lima hubo una excepción a esta regla que, al parecer, es general en los países iberoamericanos de su tiempo:

En Lima había alcanzado la mujer a gozar por lo menos dos horas en el espacio de un día, de aquella absoluta independencia que para su sexo han predicado en vano los sansimonianos. Esto se hacía y aún se hace hoy, merced a un traje que los españoles adoptaron de los árabes por espíritu religioso, y que las limeñas convirtieron en dominio por galantería. Las mujeres de Lima visten de ordinario a la europea; pero cuando quieren ser libres como las aves del cielo, solteras o casadas llevan la saya, cubren su cabeza y rostro con el manto, dejando descubierto apenas un ojo travieso y burlón, y desde ese momento todos los vínculos sociales se aflojan para ellas, si no se desatan del todo (Sarmiento, 1848, p. 9; cursiva del autor).

La absoluta independencia, la libertad que obtiene la mujer, y que la hemos visto en su viaje a París en los bailes y salones, en las aldeas de América del Norte; aquí se da en todos los ámbitos del mundo público pero a través de una vestimenta especial. Un traje en cuyo origen se encuentra la historia de la madre patria (España) antes de ser colonizadora de Hispanoamérica, pero que continúa aquí, en Lima ahora una de sus colonias, bajo otro cariz. Cual pliegues de la historia, este traje tiene en Lima otro significado, ha sido redefinido en su práctica y adoptado para adaptarse a tiempos diferentes a los de su invención. Así, la saya les permite a las mujeres enfrentar las condiciones públicas de acción. La tapada vuelve a su casa, agrega el autor, y tomando los vestidos europeos, entra en todas las condiciones de la vida ordinaria. Pero esta mascarada, este carnaval de Lima es eterno

[...] y en un baile como en un entierro, en las sesiones de las Cámaras como en la fiesta de un santo, las tapadas se presentan indistintamente, siempre impenetrables, siempre dejando adivinar con la increíble estrechez de la saya, $[\ldots]$ otras seducciones [que] la coquetería femenil sabe (Sarmiento, 1848, pp. 9-10).

En el caso de las tapadas, sus vestimentas servirían para cambiar lo que ellas eran por lo que deseaban ser, en otras palabras, cambiar su condición habitual (tal como sucedía en el "carnaval parisino"). La tapada estaba muy lejos de la angélica idealización, ¿con qué finalidad lo manifestaban? Nos arriesgamos a interpretar las funciones de ese sistema de representaciones, que conforma la tapada, como la expresión de la seducción, la libertad $\mathrm{y}$ el juego, pero fundamentalmente del ejercicio de poder intervenir y desafiar la opinión pública $y$, en cierto modo, hacerse oír.

¿Podemos pensar que la figura de la $m u-$ jer es imaginada como una intrusa porque manda cuando obedece, ordena cuando ruega e impera humillándose? ¿Cómo es esa intrusión? La tapada conforma un mito: puede ser el eterno retorno a la época colonial y, por lo tanto, la negación de la realidad circundante y del presente. Puede ser la negación de realidades evidentes. Lo femenino también asegura la perpetuidad de un modo de vida que instauró la Arcadia colo- 
nial. Entonces, Lima ingresaría a un paradigma que no necesariamente caracterizaría al atraso: es colonia, es española, es morisca, es autoritaria, es conservadora. Pero a su vez, lo femenino incorpora, utiliza, redefine las costumbres, las habitudes provenientes de las naciones modernas. Para Sarmiento: "Una ciudad montada bajo este pie de gusto y costumbres [...] no era de extrañar que no hubiese dado hasta entonces síntomas armados de participar del espíritu de la independencia que agitaba a las otras naciones americanas" (Sarmiento, 1848, p. 10).

\section{Final: el ser y el parecer}

Obtener la libertad o aparentar practicarla son dos movimientos presentes en los escritos de Sarmiento. Este tópico lo notamos en específico en el uso literario que el autor hace respecto a las figuras de la mujer. Según Sarmiento, "las mujeres son las soberanas de las costumbres del hogar". La figura de la mujer obtiene, nada más y nada menos, que una significación vital en tanto se la relaciona con la moda y las costumbres, ya que ella materializaría en la cotidianidad la vida democrática y la civilidad.

Concluimos entonces que aquí se presenta una paradoja de triple faz: el antiguo régimen asociado con la barbarie (las que leen son raras en su época) se transforma en la modernidad en un espacio donde es posible que la mujer se convierta en vanguardia en materia de enseñanza. Pero esta posibilidad choca con la existencia concreta de rasgos de alienación al consumo, a la moda y a la frivolidad, también propios de la modernidad. Las mujeres entonces participan de tres posiciones, por un lado, como objetos de la ilustración; por el otro, como intrusas en un mundo para transformarse luego en bisagras entre los pro y los contra de ambos mundos. A través de la mujer se escenifica la tensión dialéctica del momento.

Así es que se justifica que la historia de su familia y la suya propia sea construida como una homologación o, como escribiera Sarmiento, como un teatro de acción de la historia de la patria. De esta manera, a través de sus hermanas primero, de otras damas después, aparecerá la tercera posición, la de la figura del pre-texto, la mujer como excusa para criticar e intentar transformar la sociedad, la cultura y la política de su tiempo y hacer una proclama por la libertad y la igualdad que en principio no ve en la relación de los sexos entre sí (véase Goldwaser, 2010, p. 83).

En cuanto al momento en el que va tomando una posición de mayor distancia respecto a la condición de la mujer, identificamos dos "tonalidades" en sus intervenciones: una, que aparenta ser de denuncia y de persuasión para con el lector; la otra, mucho más reflexiva y quizá menos coyuntural en el que se dedicará a describir "estados generales" de la mujer en distintas partes del mundo.

Para el primer caso, la cultura de su "patria chica" (la provincia de San Juan) será el flanco para apuntar el atraso en su sociedad. Allí observa que la mujer culta (es decir, aquella que tiene capacidad/libertad de leer "como los hombres"/al igual que ellos) es una impropiedad $\mathrm{o}$, en nuestras palabras, una intrusión para la sociedad (de los hombres).

Entre la colonización y la verdadera emancipación política, se encuentra la figura de la mujer bisagra, la que cambia su condición de ser "ornamento", a un sujeto soberano. Recién allí, puede obtenerse su consentimiento para que finalmente sean los hombres quienes la representen de manera legítima. Mientras que en el primer momento sarmientino, lo intruso también era identificado en las costumbres modernas ejercidas por sus jóvenes hermanas, y que trastornaban incluso aquellos elementos sagrados; aquí, la intrusa es la madrastra España que usurpa tierras vírgenes implantando preocupaciones humillantes y costumbres aciagas en las vidas de "nuestras mujeres". Por ende, la figura objeto de (la) ilustración será la protagonista que podría subvertir el estado de cosas del mundo cotidiano. Sarmiento se pondrá más 
refinado en sus observaciones y apuntará que en el Estado moderno también persisten elementos del sistema colonial.

Lo que distinguiría a la República posrevolucionaria del orden colonial es el espacio público, con la novedad del acceso de las mujeres al mismo y su relación menos directa, pero no impugnada, con el hogar. Esta transformación se daría en parte, tanto para Sarmiento como para otros pensadores de la cofradía romántica de la Generación del 37, con la insistencia en la moda, para nada frívola, aunque sirvió de excusa para atrapar lectores y no ser censurados; para nada apolítica, porque cumplió la función de transmitir novedades y tendencias de todos los órdenes; para nada superficial, porque precisamente era necesario cambiar la apariencia de ser algo impuesto, por el ser nacional.

Pero ese ser nacional debía ocurrir en un mediano plazo. Tal como lo proclamara el padre de la primera Constitución nacional argentina, Juan B. Alberdi, la moda participa de la indecisión que afecta todas las cosas sociales. Así como no se tiene modas dominantes escribirá Alberdi en un artículo del Gacetín La Moda en 1837- no se tiene ideas, ni costumbres dominantes. Y esto implica no poseer un "punto común", ¿más próximo a la igualdad o a la homogeneización? Así, hemos intentado demostrar cómo la moda y su discurso, no solo ha sido funcional a debates de mayor envergadura para la política y la construcción del Estado nación, sino también un tópico que permitió introducir la complejidad política de pensar e instaurar la igualdad.

\section{Notas}

${ }^{1}$ Véase Higonnet (1993) y Bard (2012).

2 "Durante la primera mitad del siglo XIX la novedad desempeñó un papel central tanto en los esfuerzos por fundamentar la legitimidad política de las naciones hispanoamericanas como en la reformulación del vínculo que los sujetos establecían con el tiempo y con la historia. En la modernidad, argumentó Reinhart Koselleck (1985, p. 257), el 'pasado presente' (la experiencia) pierde peso frente al 'futuro vuelto presente' (la expectativa); el abismo que se abre entre ambos hace que el presente empiece a ser vivido como un tiempo de continua ruptura o transición, en el cual priman lo nuevo y lo inesperado" (Goldgel, 2013, p. 24).

${ }^{3}$ Para el caso argentino se lo asoció al gobierno de Bernardino Rivadavia y el empleo en la enseñanza universitaria del derecho (Myers, 2004, p. 168).

${ }^{4}$ Ampliamente desarrollada en la tesis doctoral inédita titulada: Figuras de la mujer en los proyectos nacionales. Literatura y politica en el Río de la Plata y Nueva Granada (1835 - 1853) publicada por la Universidad París 1 Panthéon Sorbonne.

${ }^{5}$ Los redactores eran, entre otros, Andrés Lamas (uruguayo), Miguel Cané y el mismo Alberdi. Fundado el 15 de abril de 1838 y su último número apareció el $1^{\circ}$ de enero de 1839 .

${ }^{6}$ Confróntese Root (2014).

${ }^{7}$ Algunos miembros de esta agrupación se formaron en universidades, muchos de ellos en la Universidad de Buenos Aires, laica e iluminista a diferencia de las universidades coloniales del resto del país. En 1838, una vez censurado el Salón Literario en la Librería Argentina de Marcos Sastre (órgano de formación de la generación), muchos de ellos debieron exiliarse. Algunos han hecho su viaje inicial al mundo de la "civilización occidental". Aquel fue un periodo prolífico en materia bibliográfica tanto en producción como en traducción e importación, así como también en fundación de periódicos, gacetas y diarios. Sin ninguna hipérbole, estas publicaciones eran herramientas de combate directo contra las ideas opresivas y conservadoras del sistema colonial y rosista. 
${ }^{8}$ Para abordar el tema "tiempos antiguos""tiempos modernos/nuevos" remitimos en especial a los capítulos $\mathrm{V}$ "La historia del pasado y la historia del porvenir" y VI "El punto de partida" de Botana (1984).

9 Confróntese Batticuore (2005), De Torres (1995), Goldgel (2013), Masiello (1997), Root (2014), entre tantos otros.

10 "Concluyamos que esa es la suerte de las mujeres: estar por un lado fuera del campo conceptual, y por el otro, bajo los fuegos de la representación imaginaria, aunque sean los de la moda. En el mejor de los casos, contribuyen a la representación simbólica [...] 'Las mujeres están de y a la moda' se entiende tanto en el sentido propio como en el figurado. Las mujeres son ya el objeto de la moda. Y como objetos a la moda, se entenderá tanto el hecho de ser las preferidas de los medios" (Fraisse, 1996, p. 13).

11 Tres meses más tarde se publicaría en forma de libro con el título Civilización y barbarie. Vida de Juan Facundo Quiroga y aspecto físico, costumbres y hábitos de la República Argentina.

\section{Referencias}

Arfuch, L. (Ed.), (2008). Mujeres y escritura(s). Crítica cultural entre política y poética (pp. 125-142). Buenos Aires: Fondo de Cultura Económica.

Bard, C. (2012). Historia política del pantalón. Buenos Aires: Tusquets.

Batticuore, G. (2005). La mujer romántica. Lectoras autoras y escritores en la Argentina. 1830 -1870. Buenos Aires: Edhasa.

Botana, N. (1984). La tradición republicana. Buenos Aires: Editorial Sudamericana.

Botana, N. (1997). La libertad política y su historia. Buenos Aires: Sudamericana.
Bourdieu, P. (Ed.). (1993). Espacio social y poder simbólico. Cosas Dichas (pp. 127142). Barcelona: Gedisa.

Fraisse, G. (1996). La diferencia de los sexos, (Trad. H. Pons). Buenos Aires: Manantial.

Goldgel, V. (2013). Cuando lo nuevo conquistó América. Buenos Aires: Siglo XXI.

Goldwaser, N. (2010). Civilización, mujer y barbarie. Una figura dislocante en el discurso político de la Generación del 37 argentina. La manzana de la discordia, 5, 79-93.

Goldwaser, N. (2013). Figuras de la mujer en los proyectos nacionales. Literatura y política en el Río de la Plata y Nueva Granada (1835 - 1853). (Tesis de Doctorado inédita). Universidad de Buenos Aires, Argentina; Université Paris 1 Panthéon Sorbonne, Paris.

Hallstead, S. (2004). Políticas vestimentarias sarmientinas: tempranos ensayos sobre la moda y el buen vestir nacional. Revista Iberoamiercana, 70(206), 53-69.

Halperín-Donghi, T. (2004). Una nación para el desierto argentino. Buenos Aires: Editores de América Latina.

Higonnet, A. (1993). "Las mujeres y las imágenes. Apariencia, tiempo libre y subsistencia" y "Mujeres e imágenes. Representaciones. En G. Fraisse y M. Perrot (Dirs.), El siglo XIX. La ruptura política y los nuevos modelos sociales (Tomo 7, pp. 267-313). Madrid: Taurus.

Ingenieros, J. (1928). Los iniciadores de la Sociología Argentina: Sarmiento, Alberdi $y$ Echeverría. Buenos Aires: Editorial Pablo Ingenieros.

Marino, M. (2013). Impresos para el cuerpo. El discurso visual del rosismo y sus inscrip- 
ciones en la construcción de la apariencia. En L. Malosetti \& M. Gené (Comps.), Atrapados por la imagen. Arte y política en la cultura impresa argentina (pp. 1945). Buenos Aires: Edhasa.

Masiello, F. (1997). Entre civilización y barbarie. Mujeres, Nación y Cultura literaria en la Argentina moderna. Rosario, Argentina: Beatriz Viterbo.

Molina, E. (2005). Civilizar la sociabilidad en los proyectos editoriales. Del grupo romántico al comienzo de su trayectoria (1837 - 1839). En G. Batticuore, K. Gallo \& J. Myers (Comps.), Resonancias Románticas. Ensayos sobre historia de la cultura argentina (1820 - 1890) (pp. 151166). Buenos Aires: Eudeba.

Myers, J. (2004). Ideas moduladas: lecturas argentinas del pensamiento político europeo. Estudios Sociales, 14(26), 161-174.

Perrot, M. (1988). ¿Es posible una historia de mujeres? Lima, Perú: Centro de la Mujer Peruana Flora Tristán.

Rodríguez-Lehmann, C. (2008). La ciudad letrada en el mundo de lo banal. Las crónicas de moda en los inicios de la formación nacional. Retóricas Banales. Moda, Política y Nación, 16(32), 203-226.

Root, R. (2014). Vestir la nación. Buenos Aires: Edhasa.
Sarmiento, D. F. (1845), Civilización y barbarie. Vida de Juan Facundo Quiroga $y$ aspecto físico, costumbres y hábitos de la República Argentina. Santiago de Chile: Imprenta del Progreso.

Sarmiento, D. F. (1848). Discurso presentado para su recepción en el Instituto Histórico de Francia. Recuperado de http://www. proyectosarmiento.com.ar

Sarmiento, D. F. (1953). Recuerdos de Provincia, Buenos Aires: Kapeluz.

Sarmiento, D. F. (1959). Textos Fundamentales (Tomo I, Selección L. Franco \& O. Amaya). Buenos Aires: Compañía General Fabril Editora.

Sarmiento, D. F. (1967). Facundo. Buenos Aires: Centro Editor de América Latina.

Sarmiento, D. F. (1996). Viajes (J. Fernández Coord. y Ed., 2da ed.). Madrid, Paris, México, Buenos Aires, Sao Pablo, Río de Janeiro, Lima: ALLCA XX; EDICIONES UNESCO.

Scott, J. (2012). Las mujeres y los derechos del hombre. Buenos Aires: Siglo XXI.

Ternavasio, M. (2009). Historia de la Argentina 1806 - 1852. Buenos Aires: Siglo XXI.

Torres De, M. I. (1995). ¿La nación tiene cara de mujer? Mujeres y nación en el imaginario letrado del siglo XIX. Montevideo: Arca. 